2. Гахов, Ф. Д. Краевые задачи [Текст] / Ф. Д. Гахов. - М.: Наука, 1977. - 640 с.

3. Гоман, О. Г. Ударное взаимодействие несжимаемой жидкости и вертикальной пластины, плавающей на ее поверхности, в условиях образования одной зоны отрыва и налички вращения [Текст] / О. Г. Гоман, В. А. Катан // Вісн. Дніпр. ун-ту. Сер.: Механіка. 2013. - Вип. 17, т. 1. - С. 191-205.

4. Кочин, Н. Е. Теоретическая гидромеханика в 2-х ч. [Текст] / Н. Е. Кочин, И. А. Кибель, Н. В. Розе. - М.: Гостехиздат, ч. 1. - 1948. - 536 с.

5. Лаврентьев, М. А. Методы теории функций комплексного переменного [Текст] / М. А. Лаврентьев, Б. В. Шабат. - М.: Наука, 1973. - 736 с.

6. Мусхелишвилли, Н. И. Сингулярные интегральные уравнения [Текст] / Н. И. Мусхелишвилли. - М.: Наука, 1968. - 512 с.

7. Седов, Л. И. Плоские задачи гидродинамики и аэродинамики [Текст] / Л. И. Седов. - М.: Наука, 1966. - 448 с.

8. Норкин, М. В. Смешанные задачи гидродинамического удара / М. В. Норкин. Ростов-на-Дону, 2007. - 136 с.

\title{
МЕТОДИКА РАСЧЕТА ВЕЛИЧИНЫ ПРОВАЛА ДАВЛЕНИЯ НА ВХОДЕ В ЭЛЕКТРОНАСОСЫ ПРИ ЗАПРАВКЕ РАКЕТОНОСИТЕЛЯ С АНАЛИЗОМ ПОЛУЧЕННЫХ ЭКСПЕРИМЕНТАЛЬНЫХ ДАННЫХ
}

\begin{abstract}
Целью исследований было определение схемы обвязки и режимов работы насосов системы заправки компонентами ракетного топлива (КРТ) баков ракетоносителя для обеспечения требований по их эксплуатации. Задачей было определение влияния параметров КРТ и гидравлической системы на величину провала давления на входе в насос. Под провалом давления понимается разница между стационарным давлением (после выхода на режим) и минимальным давлением на входе в насос. Кавитация и разнасыщение рабочей жидкости на входе в насос возможны при падении давления ниже давления насыщенных паров. Кавитация - это быстротекущие физико-механические процессы в жидкости, возникающие при уменьшении давления до величины, менышей чем давление насыщенных паров при данной температуре. При этом в отдельных местах потока возникает разрыв сплошности с заполнением пустот мелкими пузырьками насыщенного пара и выделившегося из жидкости растворенного воздуха. Кавитация, как правило, приводит к снижению напора, подачи и КПД насоса, возникновению шума и вибраций. У центробежных насосов зона возникновения кавитационных явлений находится вблизи входа в рабочее колесо. Разработана методика расчета величины провала давления на входе в насос в режиме включения при заправке РН, подтвержденная экспериментально. Включение насоса происходило при закрытом клапане на напорном трубопроводе, который открывается после выхода насоса на номинальный режим. В зависимости от времени открытия клапана меняется ускорение потока жидкости в трубопроводе. Представлены экспериментальные данные по амплитуде и длительности провала давления в зависимости от параметров КРТ и гидравлической системы.
\end{abstract}

(с) Кузьмич И. Ю., Г., Седых И. В., Минай А. В., 2019 
Показано, что для выполнения требования о включении насоса при закрытом клапане на напорном трубопроводе необходимо устанавливать клапан с электроприводом для обеспечения равномерной скорости его открытия. Показана удовлетворительная сходимость расчетных и экспериментальных данных.

Ключевые слова: кавитация, разнасыщение, провал давления, включение насоса, вибрация.

Метою досліджень було визначення схеми обв'язки і режимів роботи насосів системи заправки компонентами ракетного палива (КРТ) баків ракетоносія для забезпечення вимог по їх експлуатації. Завданням було визначення впливу параметрів КРТ і гідравлічної системи на величину провалу тиску на вході в насос. Під провалом тиску розумісться різниця між стаціонарним тиском (після виходу на режим) і мінімальним тиском на вході в насос. Кавітація і рознасичення робочої рідини на вході в насос можливі при падінні тиску нижче тиску насичених парів. Кавітація - це швидкоплинні фізико-механічні процеси в рідині, що виникають при зменшенні тиску до значення, що менше ніж тиск насичених парів при даній температурі. При цьому в окремих місцях потоку виникає розрив суцільності із заповненням пустот дрібними бульбашками насиченої пари і розчиненого повітря, яке виділилось із рідини. Кавітація, як правило, призводить до зниження напору, подачі і ККД насоса, виникнення шуму і вібрацій. У відцентрових насосів зона виникнення кавітаційних явищ знаходиться поблизу входу до робочого колеса. Розроблено методику розрахунку величини провалу тиску на вході в насос в режимі включення при заправці РН, підтверджену експериментально. Включення насосу відбувалося при закритому клапані на напірному трубопроводі, який відкривається після виходу насоса на номінальний режим. В залежності від часу відкриття клапана змінюється прискорення потоку рідини в трубопроводі. Представлено експериментальні дані по амплітуді і тривалості провалу тиску в залежності від параметрів КРТ і гідравлічної системи. Показано, що для виконання вимоги про включення насоса при закритому клапані на напірному трубопроводі необхідно встановлювати клапан 3 електроприводом для забезпечення рівномірної швидкості його відкриття. Показана задовільна збіжність розрахункових і експериментальних даних.

Ключові слова: кавітація, рознасичення, падіння тиску, вмикання насосу, вібрація.

Definition of the scheme of binding and operating modes of pumps of filling system with propellants of launch vehicle tanks for providing requirements for their operation was purpose of researches. Definition of influence of parameters of propellants for providing requirements for their operation was a task. The failure of pressure is understood as a difference between stationary pressure (after an exit to the mode) at the minimum pressure on an entrance to the pump. Cavitation and desaturation of working fluid on an entrance to the pump are possible at pressure drop lower than pressure of saturated steam. Cavitation is fast flowing physical and mathematical processes in the liquid arising at reduction of pressure up to the value smaller than pressure of saturated steam at this temperature. Thus in separate place of a stream there is rupture of a continuity with filling of emptiness with small vials of saturated steam and the dissolved air emitted from liquid. Cavitation as a rule leads to decrease in a pressure, feeding and efficiency of the pump, to emergence of noise and vibrations. At centrifugal pumps the zone of emergence of the cavitation effect is near an entrance, to the driving wheel. The method of cavitation of value of failure of pressure on an entrance to the pump in the inclusion mode with filling of launce vehicle experimentally is developed. Turing on of the pump happened at the closed valved on the pressure line which opens after a pump exit to the nominal mode. Depending on time of opening of valve accelaration of liquid stream in the pipeline changes. Experimental data of amplitude and duration of a failure of pressure depending of propellants and hydraulic system are presented. It is shown than for implementation of the requirement about turning on of the pump at the closed valve on the pressure line it is necessary to install the valve with the electric drive for ensuring uniform speed of its opening. Satisfactory convergence of estimated and experimental data is shown.

Key words: cavitation, desaturation, pressure drop, turning on of the pump, vibration.

Введение. Одним из основных требований, предъявляемых к условиям эксплуатации насосов, является отсутствие газовых включений в рабочей жидкости на входе. Наличие газовых включений на входе в насос может быть следствием кавитации или разнасыщения рабочей жидкости 
Образование газожидкостных зон в межлопастных каналах колес насосов и вызываемое ими изменение плотности рабочей среды приводит к возникновению разбалансировки, деформации вала и неравномерному изнашиванию подшипников. Неизбежное в этих условиях увеличение зазора между вращающимся колесом и неподвижными элементами корпуса насоса вызывает увеличение объемных потерь насоса и снижение его энергетических параметров, что затрудняет его штатную эксплуатацию.

Кавитация рабочей жидкости на входе в насос возможна при падении давления ниже давления насыщенных паров.

Для анализа условий, приводящих к нештатной работе насоса, проведены исследования величины провала давления на входе в насос при его включении. Под провалом давления принимается разница между стационарным давлением (после выхода на режим) и минимальным давлением на входе в насос.

Работы по определению величины провала на входе в насос проводились в два этапа:

- расчетное определение изменения давления во всасывающем трубопроводе при включении насоса;

-экспериментальное подтверждение расчетных значений.

Цель и задачи. Целью исследований было определение схемы обвязки и технологии работы насосов системы заправки КРТ баков РН для обеспечения требований по их эксплуатации. Задачами работ было определение влияния параметров системы заправки компонентами ракетного топлива на величину провала давления на входе в насос.

Методика расчета. Для проведения расчетов по определению провала давления учитывалось, что включение насоса происходит при закрытом клапане на напорном трубопроводе, который открывается только после выхода насоса на номинальный режим. В зависимости от времени открытия клапана меняется ускорение потока жидкости в трубопроводе.

В зависимости от значений ускорения и скорости меняется потребная величина энергии, которую необходимо потратить на преодоление инерционного напора и сил трения жидкости, соответственно.

Принято, что располагаемая величина энергии (давление наддува заправочной емкости, уровень компонента топлива в ней и напор насоса) - величины практически не меняющиеся.

Разница между потерями давления жидкости при работе насоса на установившемся режиме и потерями при его включении состоит в величине потерь давления на преодоление инерционного напора. Увеличение потерь давления во всасывающем трубопроводе при включении насоса за счет появления инерции жидкости, как раз и ведет к падению давления компонента топлива перед насосом.

Схема обвязки электронасоса приведена на рис. 1. Клапан с пневмоприводом, установленный на напорном трубопроводе, позволял осуществлять регулирование временем его открытия. Трубопроводы всасывания и нагнетания были заполнены компонентом. 


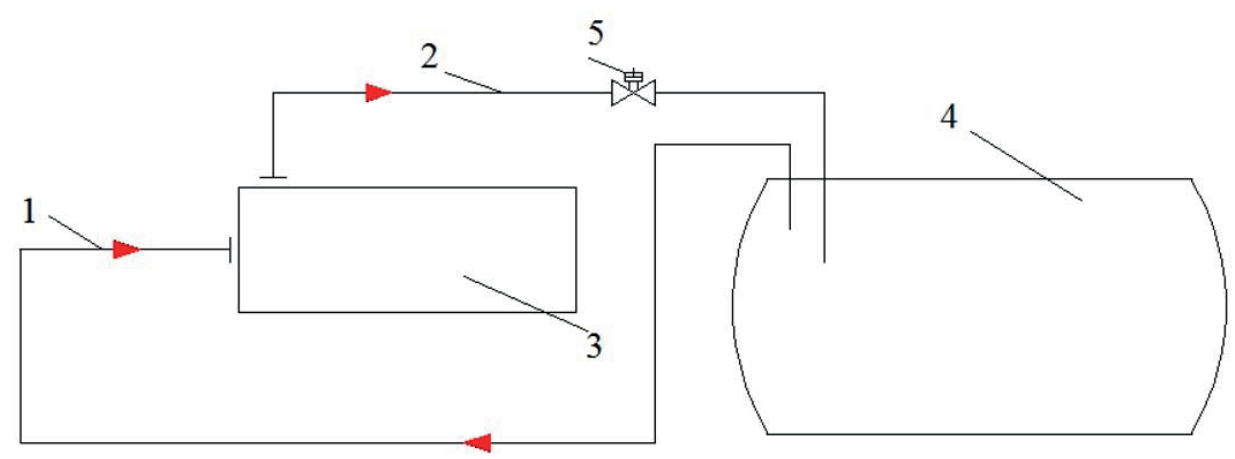

Рис. 1. Схема обвязки электронасоса:

1 - всасывающий трубопровод; 2 - напорный трубопровод; 3 - электронасос; 4 - заправочная емкость; 5 - клапан на напорном трубопроводе

Полное газовыделение происходит за промежуток времени $\geq 0,1$ с. Чтобы определить момент начала и величину провала давления при расчете брался шаг по времени $i=0,01$ с. Для каждого времени открытия клапана провал давления происходил на своем шаге.

Давление компонента топлива перед насосом определяется из уравнения Бернулли, для неустановившегося движения жидкости:

$$
p_{1}+\rho \cdot g \cdot z_{1}+\alpha \cdot \frac{\rho \cdot w_{1}^{2}}{2}=p_{2}+\rho \cdot g \cdot z_{2}+\alpha \cdot \frac{\rho \cdot w_{2}^{2}}{2}+p_{\text {п }}+p_{\text {и }},
$$

где $p_{1}, p_{2}$ - давление в различных сечениях, Па; $z_{1}, z_{2}$ - перепад уровня жидкости между заправочной емкостью и конкретным сечением, м; $w_{1}, w_{2}$-средняя скорость течения рабочей жидкости в различных сечениях, м/с; $\alpha$ - коэффициент кинетической энергии, учитывающий неравномерность распределения скоростей по течению (для турбулентного течения $\alpha=1) ; \rho$ - плотность жидкости, кг $/ \mathrm{M}^{3} ; \mathrm{g}-$ ускорение свободного падения, $\mathrm{m} / \mathrm{c}^{2} ; p_{\text {п }}$ - потери давления за счет местных потерь и потерь на трение, Па; $p_{\text {и }}-$ потери давления за счет инерционного напора, Па.

Расход рабочей жидкости определяется из уравнения Бернулли, примененного к участку напорного трубопровода.

Полагая давление на выходе из насоса $\left(p_{\text {н }}\right)$ постоянным по времени, имеем:

$$
\begin{gathered}
p_{\text {н }}=p_{\text {п }}+p_{\text {и }}, \\
p_{\Pi}=\frac{\left(1+\xi_{\mathrm{M}}+\xi_{\text {клi }}+\xi_{\text {тр } i) \cdot \rho \cdot Q^{2}}\right.}{2 \cdot S^{2}}
\end{gathered}
$$

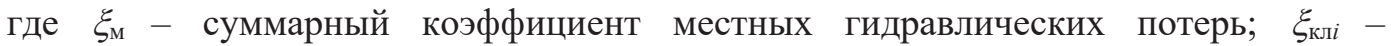
коэффициент гидравлического сопротивления клапана на напорном трубопроводе; $\xi_{\text {тр } i}-$ коэффициент гидравлического сопротивления трения; $S$ - площадь сечения трубопровода, $\mathbf{m}^{2}$;

$$
h_{\text {и }}=\frac{l \cdot a_{i}}{g},
$$

где $a_{\mathrm{i}}$ - ускорение рабочей жидкости в момент времени $t_{\mathrm{i}}, \mathrm{M} / \mathrm{c}^{2} ; h_{\mathrm{u}}-$ инерционный напор, м; $l$ - длина всасывающего трубопровода, м;

$$
\xi_{\text {тр } i}=\frac{\lambda_{i} \cdot l}{d}
$$




$$
a_{i}=\frac{w_{i}-w_{i-1}}{t_{i}-t_{i-1}}
$$

где $\lambda_{\mathrm{i}}-$ коэффициент трения, зависящий от числа Рейнольдса; $t_{\mathrm{i}}$ - выбранные моменты времени для расчета гидравлических параметров системы.

Число Рейнольдса определяется выражением:

$$
R e_{i}=\frac{w_{i} \cdot d}{v}
$$

где $w_{\mathrm{i}}$ - скорость жидкости на входе в электронасос; $d$ - диаметр напорного трубопровода, м; $v$ - коэффициент кинематической вязкости, $\mathrm{m}^{2} / \mathrm{c}$.

Коэффициент гидравлического сопротивления клапана на напорном трубопроводе зависит от высоты подъема тарели. При расчетах было принято, что скорость движения тарели клапана по времени не меняется.

Разрешив уравнение (3) относительно $Q_{i}$, получим выражение

$$
Q_{i}=\sqrt{\left(\frac{2 \cdot\left(p_{\mathrm{H}}-\rho \cdot g \cdot h_{\mathrm{Mi}}\right)}{\rho}\right) \cdot\left(\frac{\xi_{\mathrm{M}}+\xi_{\mathrm{\kappa лi}}+\xi_{\mathrm{Tp} i}+1}{S^{2}}\right)^{-1}},
$$

которое дает зависимость расхода жидкости от хода клапана.

Давление компонента топлива во всасывающем трубопроводе (в сечении перед насосом) при включении насоса является функцией вида $p=F\left(\xi_{\text {кл } i}, \xi_{\text {тр } i, w_{i}, t_{i}, l, \rho}\right.$ ) и определяется из уравнения:

то есть

$$
p=p_{\text {зе }}+\rho \cdot g \cdot h-p_{\text {п }}-p_{\text {и }},
$$

$$
p_{i}=p_{\text {зе }}+\rho \cdot g \cdot h-p_{\text {пi }}-p_{\text {иi }}=\gamma \cdot\left(\frac{p_{\text {зе }}}{\gamma}+h-h_{п i}-h_{\text {иi }}\right),
$$

где $p_{3 \mathrm{e}}$ - давление в заправочной емкости, Па; $h_{\text {пi }}$ - потери напора за счет местных потерь и потерь на трение, Па; $h_{\text {иi }}$ - потери напора за счет инерции, Па.

Исследование зависимости величины провала давления от параметров КРТ и гидравлической системы проводилось для центробежных герметичных электронасосов ЦГЭН восьми типоразмеров (подача электронасосов находится в

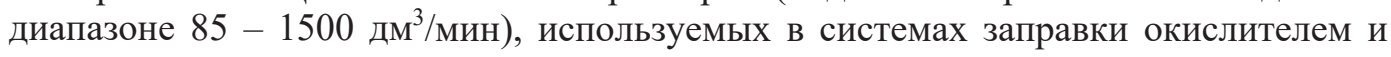
горючим.

В качестве рабочей жидкости использовались компоненты топлива:

- $\quad$ тетраоксид диазота $\left(\rho=1488 \kappa \Gamma / \mathrm{M}^{3}\right)$;

- несимметричный диметилгидразин $\left(\rho=810\right.$ кг/м $\left.{ }^{3}\right)$.

В качестве исходной эмпирической базы данных для определения коэффициентов распределенных и местных гидравлических потерь использовались данные справочника И. Е. Идельчика [4].

В качестве исходных данных для расчета провала давления на входе в электронасос было принято:

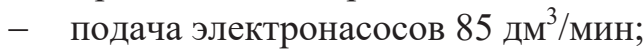

- температура компонентов топлива $1^{0} \mathrm{C}$;

- $\quad$ время открытия клапана на напорном трубопроводе задано 0,$5 ; 2 ; 5$ с.

Расчетные значения давления на входе в электронасос при его включении приведены на рис. 2 и рис. 3. На графиках приведены: 
$\Delta \mathrm{p}_{0}$ - номинальное допустимое значение давления, исключающее газовыделение; $\Delta \mathrm{p}_{0 \min }$ - минимальное допустимое значение давления, исключающее газовыделение; $\mathrm{p}_{\min }$ - давление, при снижении ниже которого происходит полное газовыделение.

Расчетные зависимости провала давления от времени открытия клапана для электронасосов окислителя (ЦГЭН-О3) и горючего (ЦГЭН-ГЗ) приведены на рис. 4.

Экспериментальные данные для ЦГЭН-О3 и ЦГЭН-ГЗ были получены для времени открытия 4 с, сходимость составила $15-20 \%$.

По результатам проведенных расчетов получена зависимость провала давления от времени открытия клапана на напорном трубопроводе и плотности КРТ. Как видно, с увеличением времени открытия клапана величина провала давления снижается, причем величина провала давления пропорциональна плотности КРТ. С учетом полученных данных было принято решение об установке на напорном трубопроводе электронасосов, обеспечивающих заправку $\mathrm{PH}$, а также клапана с электроприводом для обеспечения равномерного открытия.

Результаты экспериментальных исследований. Экспериментальное определение влияния параметров КРТ и гидравлической системы на величину провала давления проводилось для электронасосов, обеспечивающих подготовку КРТ к заправке РН, путем последовательного изменения:

- подачи электронасоса;

- времени открытия клапана на напорном трубопроводе;

- температуры КРТ;

- рабочей жидкости.

Провал давления на входе в электронасос определялся амплитудой и длительностью восстановления до стационарного давления.

Результаты экспериментального определения влияния величины подачи рабочей жидкости и времени открытия клапана (в режиме включения электронасоса) на амплитуду провала давления приведены на рис. 6,7 и в таблице 1; на длительность провала давления - на рис. 8 .

Таблий 1

Влияние времени открытия клапана на величину провала давления

\begin{tabular}{|c|c|c|c|c|}
\hline \multirow{2}{*}{$\begin{array}{l}\text { Время открытия } \\
\text { клапана, с }\end{array}$} & \multirow{2}{*}{$\begin{array}{l}\text { Давление на } \\
\text { входе, } 10^{5} \text { Па }\end{array}$} & \multirow{2}{*}{$\begin{array}{l}\text { Температура } \\
\text { KРT, }{ }^{\circ} \mathrm{C}\end{array}$} & \multicolumn{2}{|c|}{ Величина провала давления, $10^{5}$ Па } \\
\hline & & & $\mathrm{Q}=1000$ дм $^{3} /$ мин & $\mathrm{Q}=400$ дм $^{3} / \mathrm{мин}$ \\
\hline 5 & \multirow{4}{*}{$2,5-3,5$} & \multirow{4}{*}{$1-3$} & 1,89 & 0,52 \\
\hline 4 & & & 1,92 & 0,81 \\
\hline 3 & & & 2,01 & - \\
\hline 2 & & & 2,04 & 1,07 \\
\hline
\end{tabular}

Таким образом, с увеличением ускорения рабочей жидкости при включении электронасоса, которое определяется расходом КРТ и скоростью открытия клапана, величина провала давления возрастает.

Длительность провала давления более 0,1 с ниже минимально-необходимой величины для исключения газовыделения и отсутствия кавитации является критичной, так как при этом успевает произойти полное газовыделение [1]. 


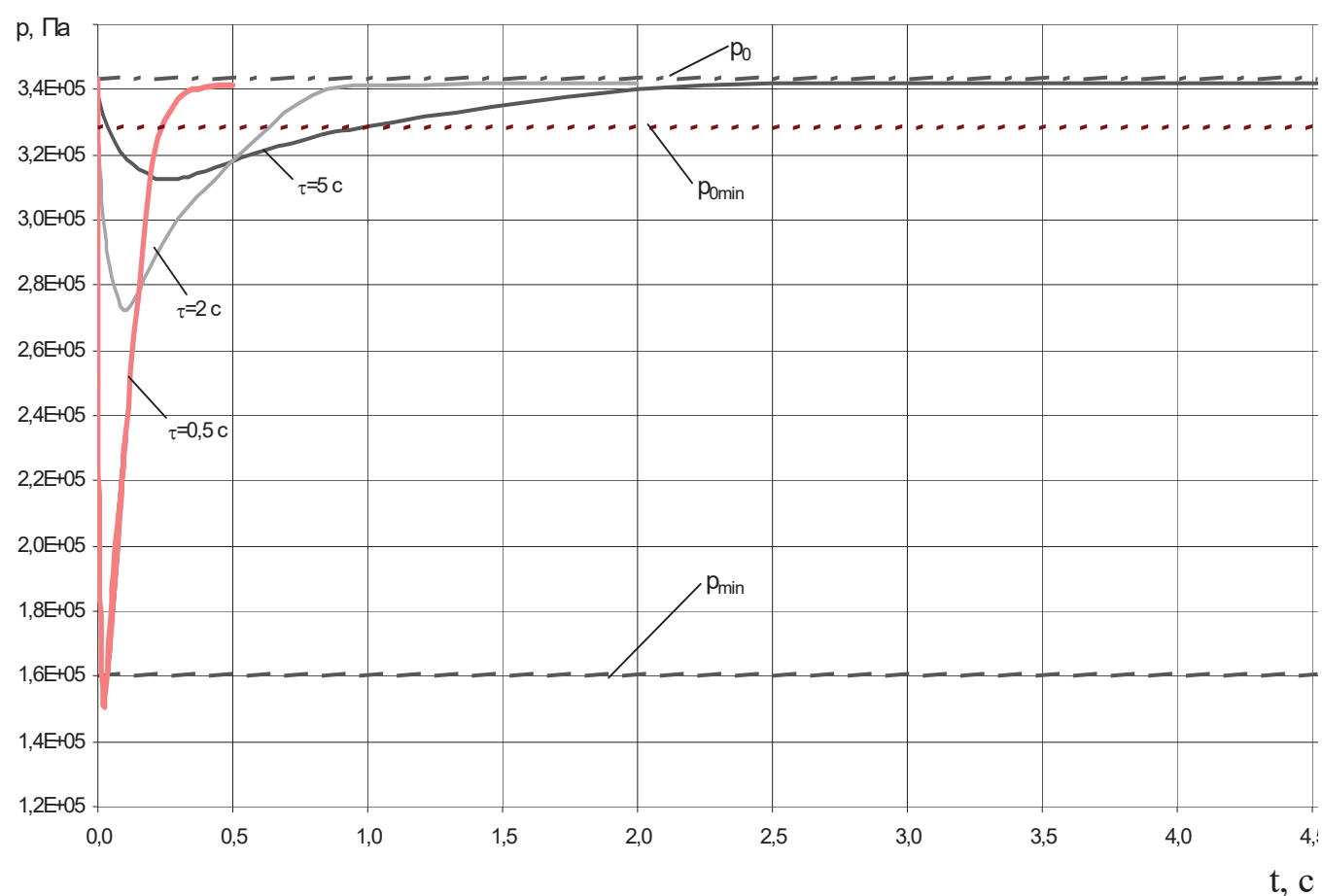

Рис. 2. Расчетные значения зависимости величины давления окислителя от времени открытия клапана за электронасосом

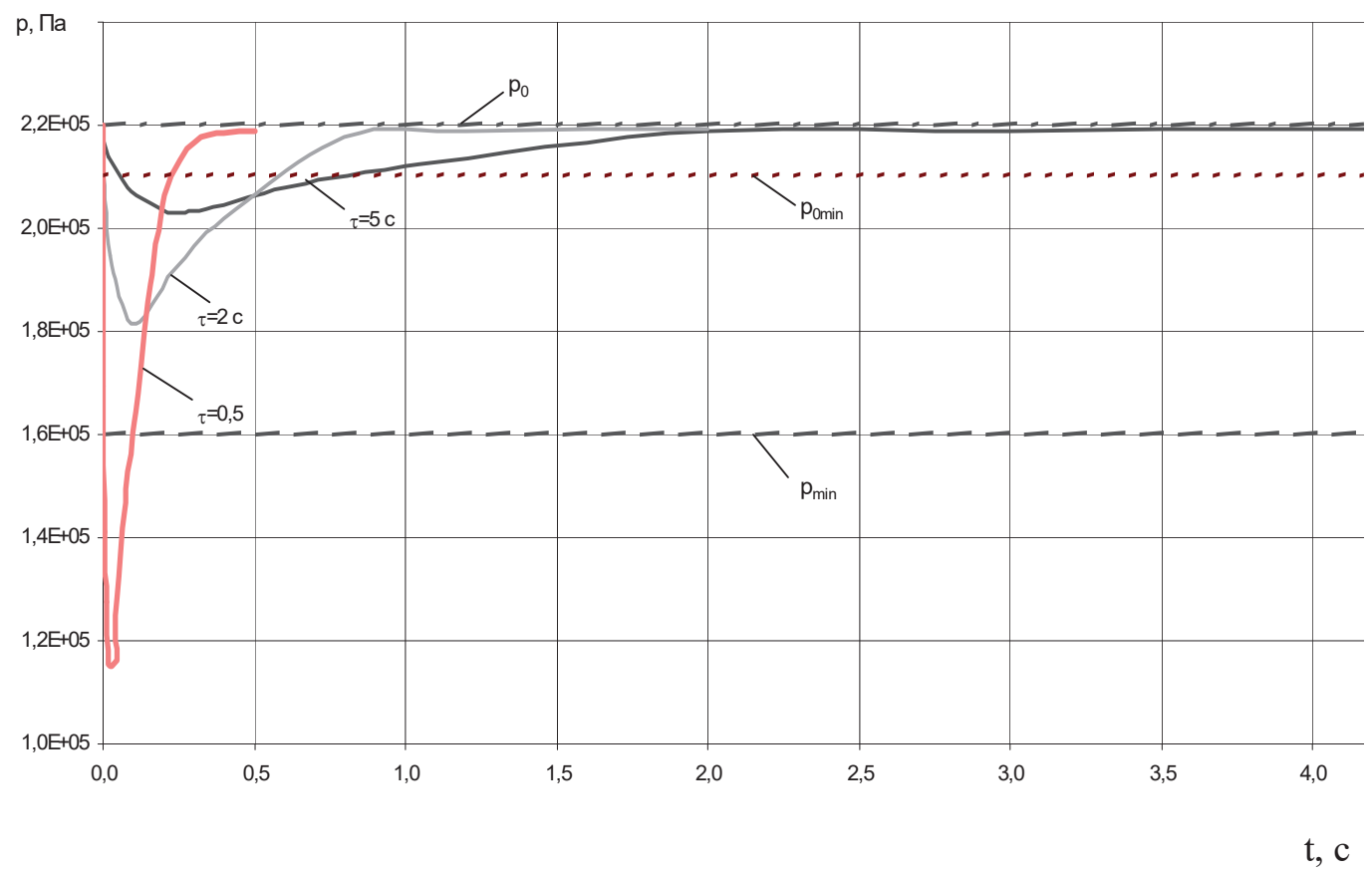

Рис. 3. Расчетные значения зависимости величины давления горючего от времени открытия клапана за электронасосом 


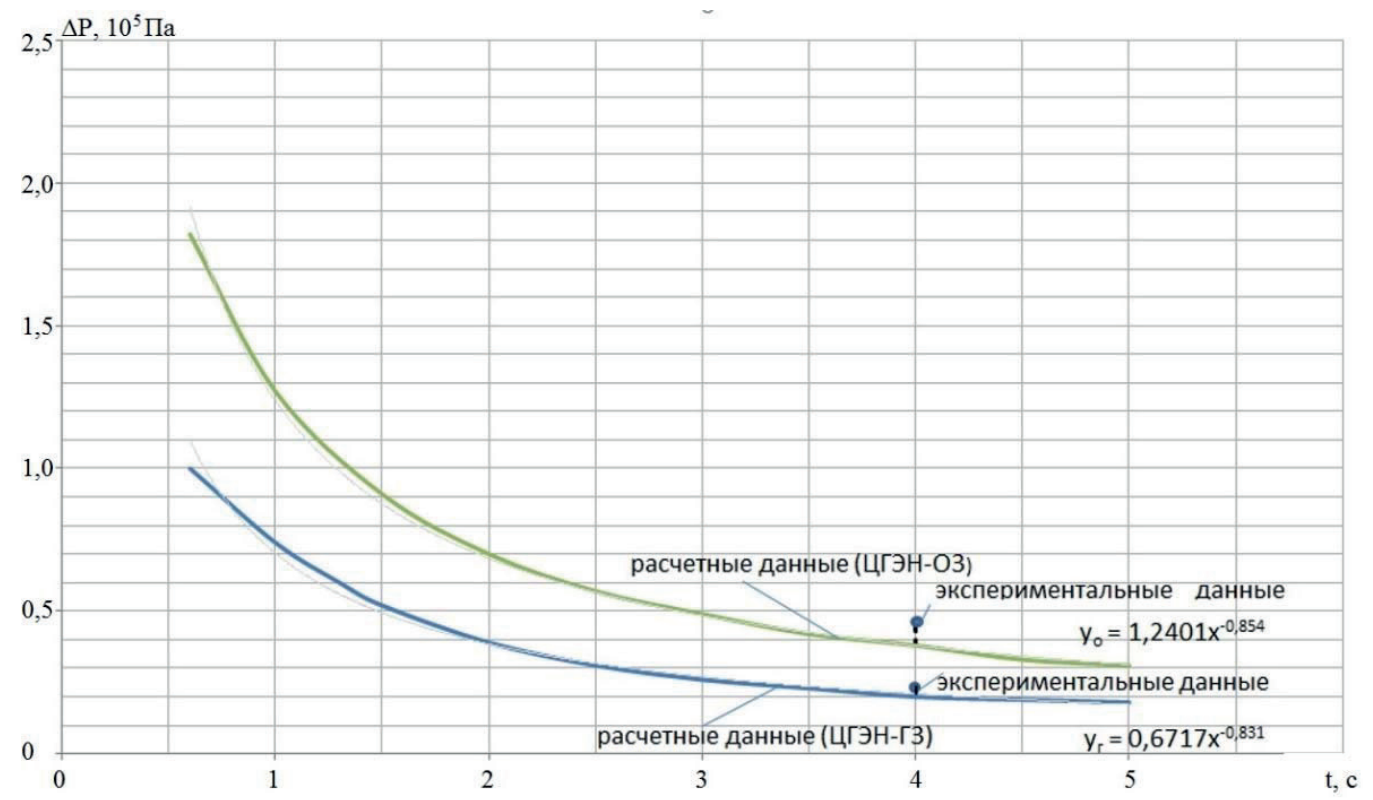

Рис. 4. Расчетные зависимости провала давления от времени открытия клапана для электронасосов окислителя и горючего

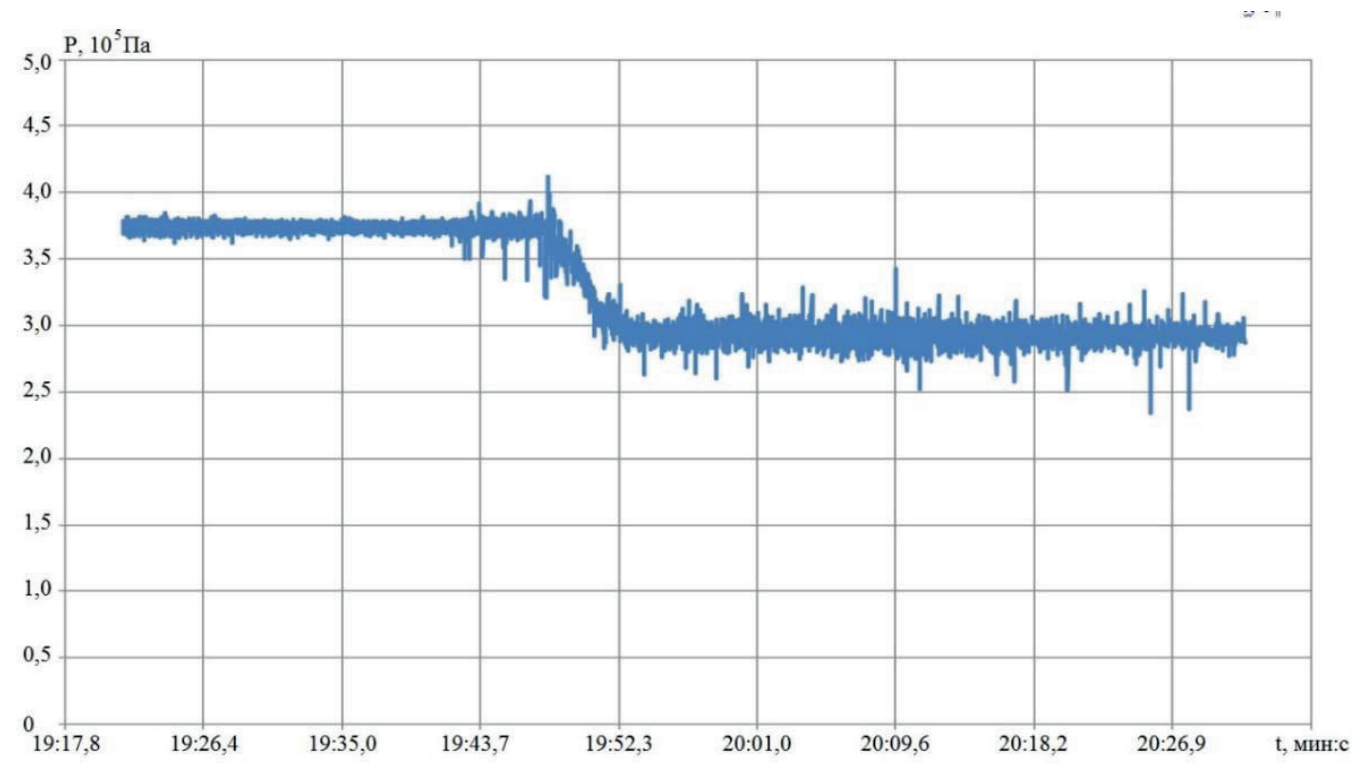

Рис. 5. Экспериментальная зависимость давления на входе в электронасос от времени (при расходе 1500 л/мин, время открытия клапана 5 с) 


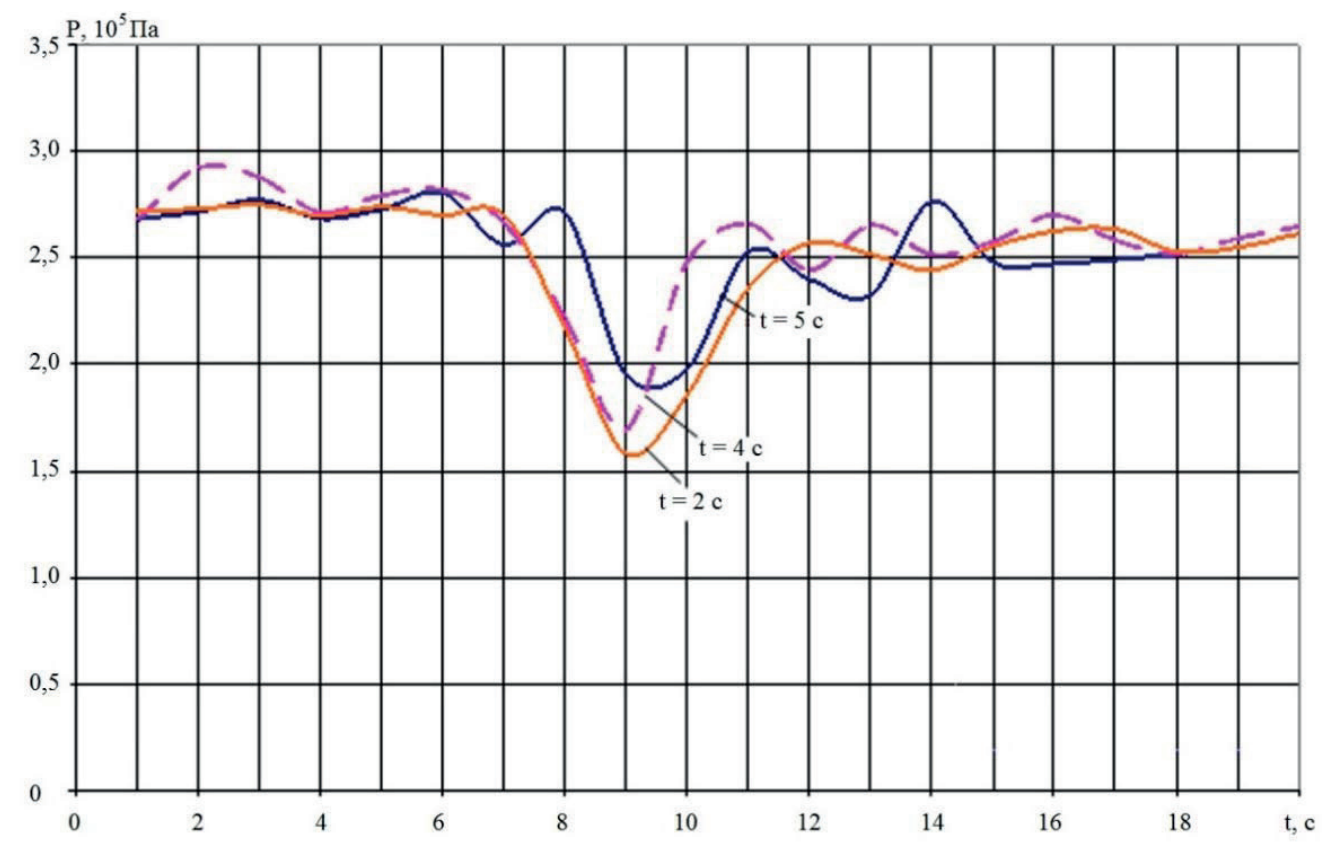

Рис. 6. Экспериментальная зависимость давления на входе в электронасос от времени в режиме включения (для различных времен открытия клапана, при расходе 400 дм³/мин)

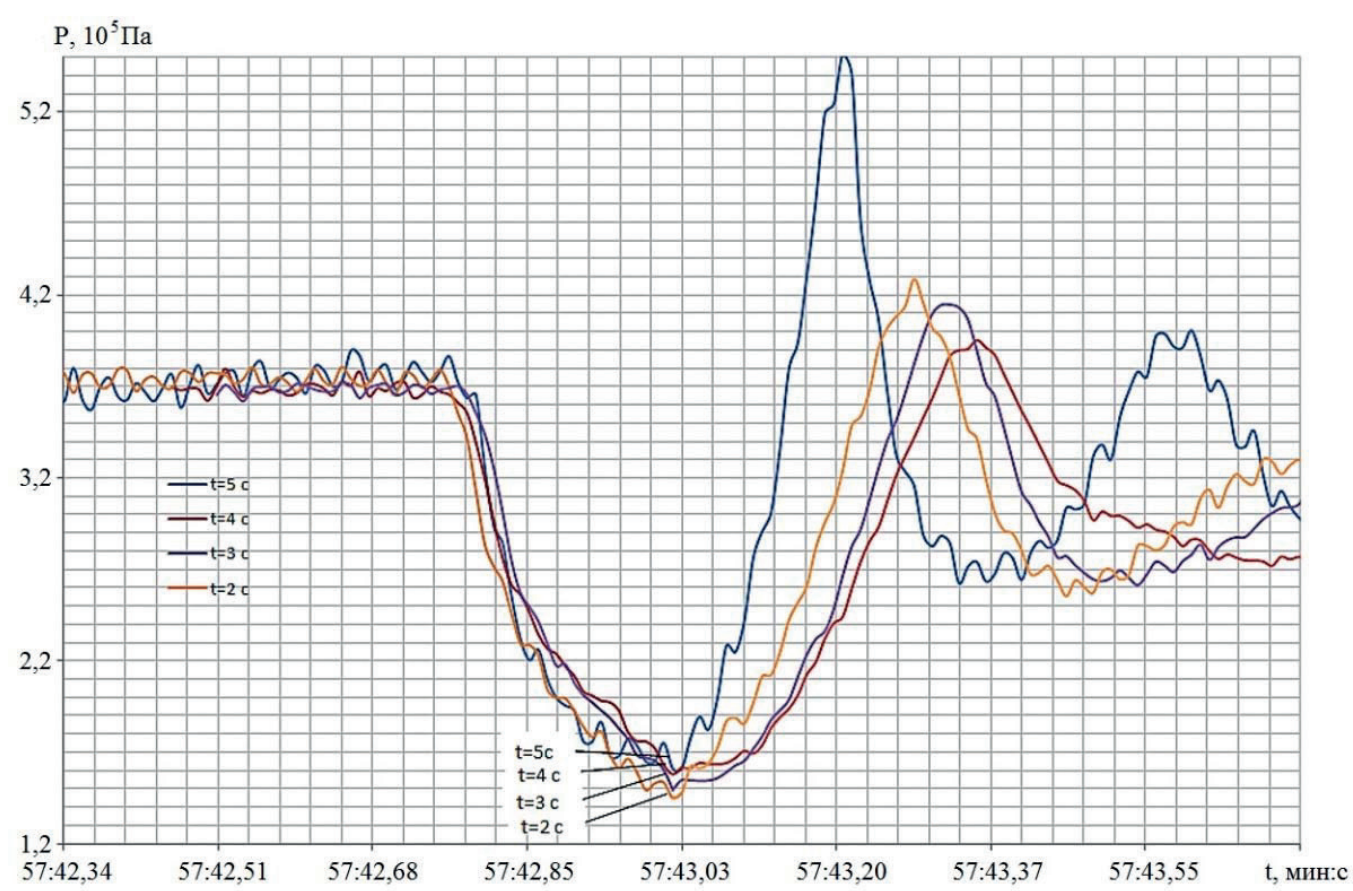

Рис. 7. Экспериментальная зависимость давления на входе в электронасос от времени в режиме включения (для различных времен открытия клапана, при расходе 1000 дм³/мин) 
$\Delta \mathrm{P}, 10^{5}$ Па

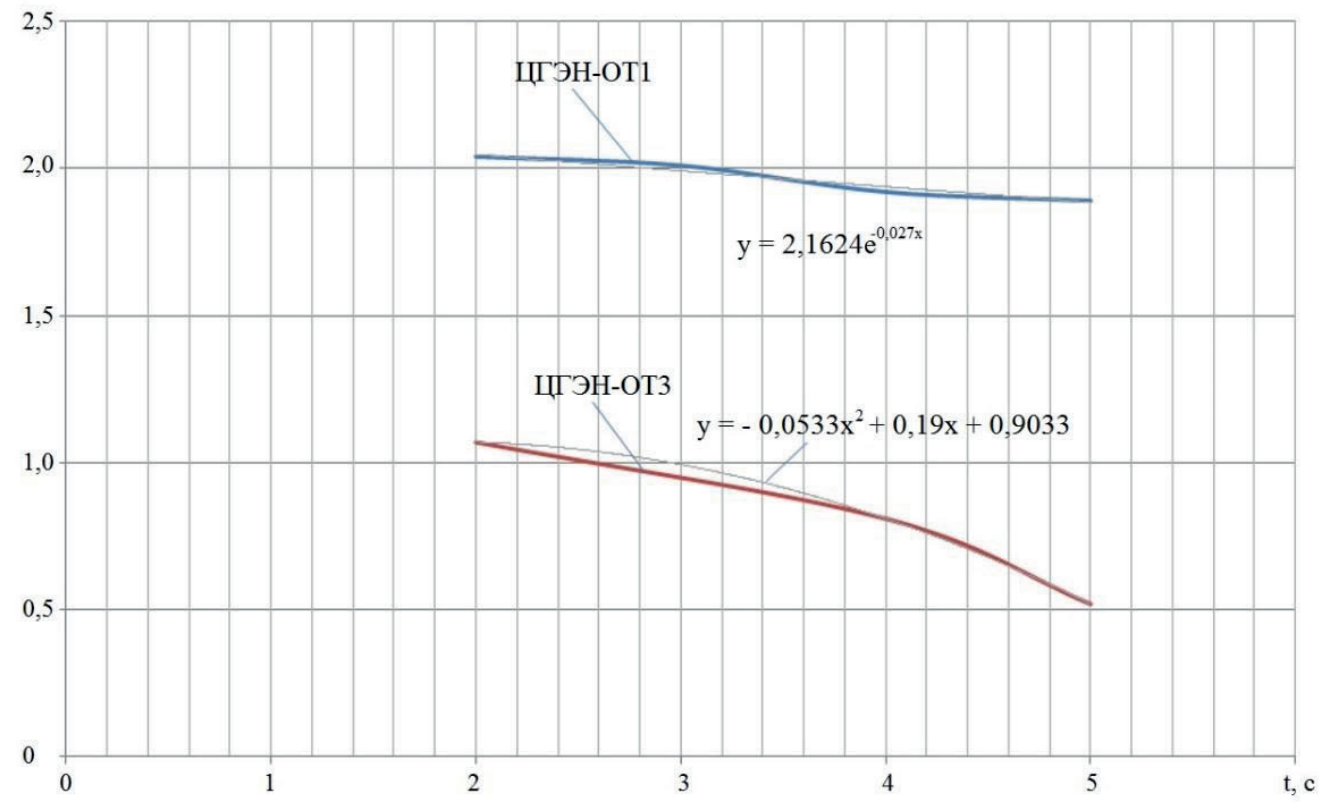

Рис. 8. Экспериментальная зависимость величины провала давления на входе в электронасос от времени открытия клапана на напорном трубопроводе

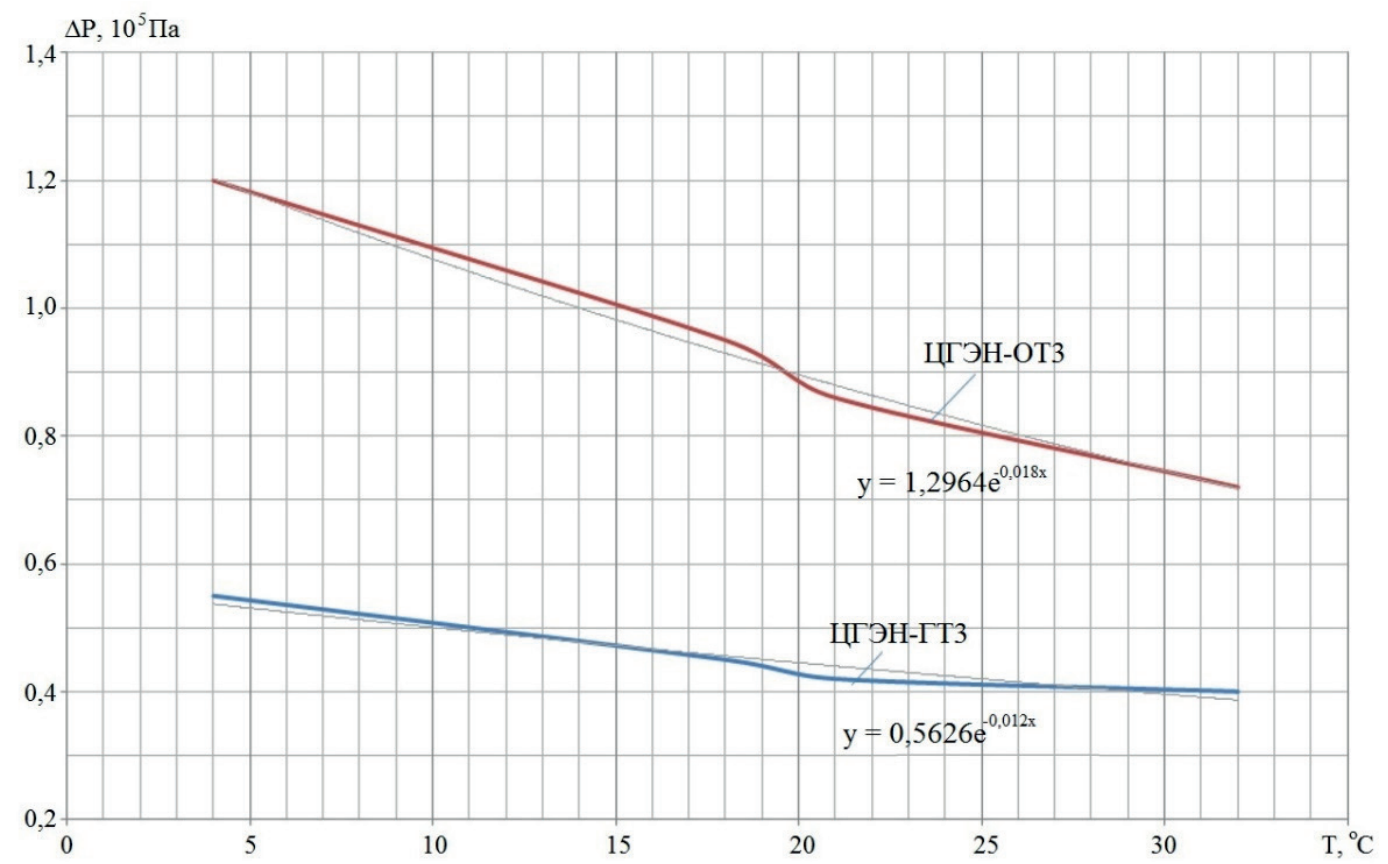

Рис. 9. Экспериментальная зависимость величины провала давления от температуры рабочей жидкости

Результаты экспериментального определения влияния температуры и соответственно плотности рабочей жидкости на величину провала давления приведены на рис. 9 и в таблице 2. 
Таблица 2

Влияние плотности рабочей жидкости на величину провала давления

\begin{tabular}{|c|c|c|c|c|}
\hline \multirow{2}{*}{$\begin{array}{l}\text { Подача, } \\
\text { дм }{ }^{3} \text { мин }\end{array}$} & \multicolumn{2}{|l|}{ Горючее (ЦГЭН-ГТ3) } & \multicolumn{2}{l|}{ Окислитель (ЦГЭН-ОТ3) } \\
\cline { 1 - 5 } & $\begin{array}{l}\text { Величина провала } \\
\text { давления, } 10^{5} \text { Па }\end{array}$ & Плотность, кг/дм ${ }^{3}$ & $\begin{array}{l}\text { Величина провала } \\
\text { давления, } 10^{5} \text { Па }\end{array}$ & Плотность, кг/дм ${ }^{3}$ \\
\hline 233 & 0,55 & 0,8070 & 1,20 & 1,4814 \\
\hline 233 & 0,45 & 0,7930 & 0,95 & 1,4506 \\
\hline 233 & 0,41 & 0,7895 & 0,86 & 1,4439 \\
\hline 233 & 0,40 & 0,7782 & 1,07 & 1,4188 \\
\hline 333 & 0,65 & 0,8110 & 1,10 & 1,4900 \\
\hline 333 & 0,63 & 0,8090 & 0,94 & 1,4771 \\
\hline 333 & 0,60 & 0,8050 & 1,20 & 1,4900 \\
\hline 400 & 0,70 & 0,8110 & 1,10 & 1,4879 \\
\hline 400 & 0,69 & 0,8100 & 0,79 & 1,4234 \\
\hline 400 & 0,58 & 0,7802 & & \\
\hline
\end{tabular}

Из таблицы 2 видно, что увеличение плотности КРТ приводит к возрастанию величины провала давления. При изменении рабочей жидкости величина провала давления в среднем остаётся пропорциональной плотности КРТ, однако при изменении температуры КРТ пропорциональность не сохраняется (за счет погрешности средств измерения при испытаниях и незначительном изменении плотности в зависимости от температуры).

Определение влияния длины и диаметра всасывающего трубопровода на величину провала давления не проводилось.

Выводы. Разработана методика расчета провала давления на входе в электронасос при его включении, которая подтверждена экспериментально. Сходимость расчетных и экспериментальных значений провала давления составляет менее $15-20 \%$.

Величина провала давления зависит от следующих факторов:

- плотности рабочей жидкости;

- ускорения рабочей жидкости во всасывающем трубопроводе, которое, в свою очередь, определяется величиной расхода КРТ и временем открытия клапана на напорном трубопроводе;

- длины и диаметра всасывающего трубопровода.

Длительность провала давления зависит от времени открытия клапана на напорном трубопроводе и от величины расхода.

Во избежание возникновения провала давления на входе в насос при требовании его включения при закрытом клапане на напорном трубопроводе целесообразно использовать клапан с электроприводом, обеспечивающим плавное открытия.

\section{Библиографические ссылки}

1. Ермашкевич, В. Н. Гидро- и термодинамика насосных систем энергоустановок на четырехокиси азота [Текст] / В. Н. Ермашкевич// - Минск: «Наука и техника», 1987. - 285 с.

2. Карелин, В. Я. Кавитационные явления в центробежных и осевых насосах [Текст] / В. Я. Карелин// - М.: «Машиностроение», 1975. - 335 с. 
3. Калекин, А. А. Гидравлика и гидравлические машины [Текст] / А. А. Калекин// М.: «Мир», 2005. -512 с.

4. Идельчик, И. Е. Справочник по гидравлическим сопротивлениям [Текст] / И. Е. Идельчик// - М.: «Машиностроение», 1975. - 560 с.

Надійшла до редколегї 12.08.2019

УДК 532.516

\author{
Д. А. Редчиц*, С. В. Моисеенко**, И. Б. Чашина*, И. В. Выгоднер** \\ *Институт транспортных систем и технологий НАН Украины \\ **Херсонский национальный технический университет
}

\title{
ОБТЕКАНИЕ ЦИЛИНДРА И АЭРОДИНАМИЧЕСКОГО ПРОФИЛЯ С УЧЕТОМ ЛАМИНАРНО-ТУРБУЛЕНТНОГО ПЕРЕХОДА
}

\begin{abstract}
Проведено моделирование обтекания цилиндра и профиля NACA 4412 с использованием $\gamma$ Reө модели ламинарно-турбулентного перехода и без нее. Численное моделирование выполнено на базе осредненных по Рейнольдсу уравнений Навье-Стокса (URANS), с использованием дифференциальной однопараметрической модели турбулентности Spalart-Allmaras. Система исходных уравнений, записывалась относительно произвольной криволинейной системы координат. Согласование полей давления и скорости осуществлялось с помощью метода искусственной сжимаемости, модифицированного для расчета нестационарных задач. Интегрирование системы исходных уравнений проводилось численно с использованием метода контрольного объема. Для конвективных потоков использовалась противопоточная аппроксимация Rogers-Kwak, основанная на схеме Roе третьего порядка точности. В моделях турбулентности для аппроксимации конвективных слагаемых применялась схема TVD c ограничителем потоков ISNAS третьего порядка. Проведено сравнение результатов расчетов обтекания цилиндра с использованием модели ламинарно-турбулентного перехода и без нее. Показано, что при низких числах Рейнольдса, когда обтекание цилиндра носит ламинарный характер, а след турбулентный, использование модели турбулентности Spalart-Allmaras приводит к развитию турбулентного пограничного слоя на цилиндре и, как следствие, к изменению положения точки отрыва. Неправильное положение точки отрыва оказывает влияние на распределение давления в донной части цилиндра и на интегральные аэродинамические характеристики. Применение модели перехода позволяет адекватно воспроизвести ламинарный отрыв вблизи передней кромки профиля с последующим его присоединением. Применение одной только модели Spalart-Allmaras приводит к излишней генерации турбулентной вязкости. Показано, что применение $\gamma$-Re $\operatorname{Re}_{\theta}$ модели ламинарнотурбулентного перехода качественно и количественно улучшает результаты численного моделирования. Полученные результаты численного моделирования обтекания кругового цилиндра и аэродинамического профиля NACA 4412 хорошо согласуются с экспериментальными данными в широком диапазоне чисел Рейнольдса.

Ключевые слова: ламинарно-турбулентный переход, аэродинамический профиль, уравнения Навье-Стокса, модель турбулентности.
\end{abstract}

Проведено моделювання обтікання циліндра і профілю NACA 4412 з використанням $\gamma$-Reo моделі ламінарно-турбулентного переходу і без неї. Чисельне моделювання виконано на базі осереднених за Рейнольдсом рівнянь Нав'є-Стокса (URANS), з використанням диференціальної однопараметричної моделі турбулентності Spalart-Allmaras. Система вихідних рівнянь, записувалася щодо довільної криволінійної системи координат.

(с Редчиц Д.А., Моисеенко С.В., Чашина И. Б., Выгоднер И.А., 2019 